\title{
Combatir y conservar: posiciones y saberes sobre el lenguaje popular en los Boletines de la Academia Argentina de Letras (1933-1943)
}

Mara Glozman

\section{Resumen}

Este artículo presenta un análisis de las posiciones y los saberes acerca del lenguaje popular formulados en los Boletines de la Academia Argentina de Letras (BAAL) durante los primeros diez años de la publicación (1933-1943). Se trata de una problemática recurrente en los BAAL, cuya relevancia histórica se profundizó a partir de las transformaciones socio-económicas, políticas y culturales que tuvieron lugar desde comienzos de la década de 1930. En términos teóricos, el trabajo se filia en los estudios de Glotopolítica tal como se desarrollan actualmente en la Argentina, considerando a su vez aportes de diversos enfoques disciplinares. Metodológicamente, el trabajo pone en serie formulaciones sobre la Argentina, el lenguaje y los géneros asociados a la cultura popular, formulaciones que -en su dispersión-responden a un mismo posicionamiento político-institucional. Por su importancia discursiva, el análisis se detiene especialmente en el funcionamien to de la dicotomía campo-ciudad, privilegiando dos ejes: a) la relación entre las definiciones políticas generales que se formulan en los BAAL y los posicionamientos sobre la cultura y el lenguaje popular y b) los saberes especializados que construyen al lunfardo, al folklore y a la poesía considerada popular como objetos de descripción y prescripción. El trabajo se propone, así, dar cuenta de los modos en los cuales la Academia contribuyó a institucionalizar un imaginario de lenguaje popular vinculado, por un lado, a una determinada definición de la tradición $y$, por el otro, a las políticas de exclusión de las prácticas asociadas al espacio popular urbano.

Palabras clave:Glotopolitica, Academia Argentina de Letras, lenguaje popular, tradición, lunfardo, folklore. 


\section{Introducción}

La Academia Argentina de Letras (AAL) fue creada en 1931 por un decreto-ley del primer presidente de facto de la historia Argentina, José F. Uriburu. Según especificaba el texto legal que la instituyó, la AAL tenía entre sus objetivos "velar por la corrección y pureza del idioma", estudiar las "particularidades" lingüísticas de la Argentina, asesorar a las reparticiones y organismos del Estado nacional en materia lingüística, así como regular el campo cultural a través - por ejemplo- de la asignación de premios literarios y del control sobre la producción teatral nacional ("Decreto de creación", en Academia Argentina de Letras, 2001, p. 8). La Corporación, por lo tanto, tenía asignadas funciones diversas, que respondían a su compleja articulación político-institucional.

Por un lado, la AAL asumía funciones propias de las academias de la lengua, en particular -siguiendo las definiciones de Barrios (2010)- la promoción de una política basada en el purismo idiomático y el afán de instituir criterios de corrección que proyectaran un determinado imaginario de unidad lingüística. No obstante, como han señalado Blanco (1994 y 1995) y Taboada (1999), comprender el alcance de la AAL en lo atinente a las tareas de fijación normativa y de codificación lingüística implica considerar el papel subalterno que las academias americanas cumplieron históricamente en relación con la Real Academia Española (RAE). En efecto, si bien no se creó como una institución correspondiente de la RAE, los fines que la AAL tenía asignados la inscribían en el conjunto de las academias normativas hispanoamericanas, la gran mayoría de ellas formalmente dependientes de la RAE.

Por otro lado, la Academia debía funcionar en gran medida como un organismo político-cultural, interviniendo en cuestiones que en principio podrían ser consideradas ajenas a la regulación lingüística, tales como el teatro, la producción y difusión literaria, y las concepciones generales en torno de la cultura nacional. En este sentido, aun cuando la Corporación contara hasta 1949 con una relativa autonomía respecto de las políticas gubernamentales (GLOZMAN, 2009), la AAL formaba parte del conjunto de instituciones oficiales que sustentaban las políticas culturales del Estado nacional.

Este trabajo presenta un análisis de los posicionamientos que orientaron la labor de la AAL en sus inicios, atendiendo específicamente a una de las problemáticas que emergieron con mayor recurrencia en los Boletines de la Academia Argentina de Letras (BAAL) durante los primeros diez años de la publicación (1933-1943): la cuestión del lenguaje popular. Analizar los modos en que se configuraron los posicionamientos y saberes en torno de lo popular permite comprender uno de los puntos de articulación entre las posiciones puristas y prescriptivas en materia lingüística y las concepciones político-culturales más generales 
que sustentaron la intervención normativa de la Corporación. Con ello, el trabajo se propone contribuir a estudiar aspectos -poco considerados hasta el momento- del papel institucional, políticolingüístico y cultural de la AAL durante sus primeras décadas de funcionamiento.

El trabajo se inscribe en el campo de la Glotopolítica (ARNOUX, 2008; ARNOUX \& BEIN, 2010; ARNOUX \& DEL VALLE, 2010), que se propone estudiar las relaciones entre las posiciones en torno de la lengua y del lenguaje, por un lado, y los procesos políticos, sociales y culturales más amplios en los que tales posiciones se inscriben. La Glotopolítica opera con materiales de archivo de diversa naturaleza genérica -normas jurídicas, manuales y programas de estudio, materiales pedagógicos, diccionarios, gramáticas, entre otros (ARNOUX \& LUIS, 2003)-, considerando en las series textuales que constituye para el análisis tanto su dimensión histórica como su dimensión discursiva. El enfoque glotopolítico, en este sentido, confluye con los estudios de historia de las ideas lingüísticas (AUROUX, 1989 y 2008), puesto que se detiene mayormente en aquellos textos que configuran lo lingüístico no solo como objeto de valoración y de prescripción sino también en tanto objeto de saber, atendiendo específicamente a los lugares institucionales en los cuales los saberes se formulan y circulan (ORLANDI, 2002; MARIANI \& GOMES DE MEDEIROS, 2007).

Por otra parte, dada la especificidad de la institución y de los materiales que el análisis aborda, el trabajo también considera los aportes provenientes de otros campos disciplinares, como investigaciones sobre historia intelectual en la Argentina y los estudios culturales (WILLIAMS, 2000 y 2001), que proporcionan herramientas productivas para comprender algunas cuestiones político-institucionales o político-culturales que tienen efectos de sentido en las posiciones en torno del lenguaje formuladas en los BAAL.

\section{Los Boletines de la Academia Argentina de Letras y la cuestión de lo popular}

Si bien la creación de la AAL fue una medida oficial de quien asumió la Presidencia de la Nación luego de encabezar el golpe de Estado que derrocó en 1930 a Hipólito Yrigoyen, la composición de la Academia durante sus primeras décadas no fue homogénea. La Institución incorporó, ciertamente, a figuras que habían participado del golpe de Estado y adherido al programa corporativista de Uriburu, entre ellas Carlos Ibarguren, identificado en términos generales con aquella línea político-cultural que Buchrucker (1999) denomina nacionalismo restaurador. La AAL designó como miembros, asimismo, a personalidades del campo literario y pedagógico de filiación hispanista, como Calixto Oyuela -primer presidente de la AAL- y a intelectuales vinculados con las instituciones y publicaciones católicas -tal era el caso de monseñor Gustavo 
Franceschi y de Juan Alfonso Carrizo. Pero también incluyó a figuras representativas de corrientes del saber que respondían a concepciones sociales y epistemológicas diferentes -por ejemplo Rodolfo Senet, pedagogo positivista con una extensa trayectoria en la Psicología experimental.

Los BAAL comenzaron a publicarse en 1933, dos años después de la creación de la Corporación. Se trató, desde sus inicios, de una publicación periódica que incorporaba una diversidad de textos, heterogéneos tanto en sus temáticas como en su dimensión genérica, puesto que incluía, entre otros, notas biográficas, artículos de autor e informes oficiales. Los $B A A L$ constituyeron en gran medida una expresión y a la vez una instancia de formulación y puesta en circulación de los posicionamientos políticos más generales, de los enfoques de estudio que primaban en la AAL y de los campos del saber en los cuales se legitimaba la intervención normativa de la Corporación.

El primer ciclo de publicación de los BAAL (1933-1943) coincidió con una etapa en la cual comenzaban a operarse -tanto a nivel nacional como regional- transformaciones económicas, sociales y productivas de envergadura. Principalmente, tales transformaciones estuvieron vinculadas con el proceso de desarrollo industrial -paulatino a comienzos de la década y sostenido desde mediados del decenio de 1930- surgido de la tendencia creciente a la sustitución de importaciones como mecanismo de salvaguarda de los intereses de los sectores dominantes frente a las políticas proteccionistas de los países centrales (DEL CAMPO, 2005). El acelerado crecimiento de las manufacturas locales tuvo fuertes efectos sociales y demográficos, vinculados con la migración de una importante cantidad de trabajadores rurales y de habitantes de las provincias del Norte de la Argentina hacia las zonas urbanas en proceso de desarrollo industrial.

Estos cambios tuvieron efectos, asimismo, en otras dimensiones sociales, atinentes a las prácticas y políticas culturales, así como a aspectos relacionados con las posiciones en torno del lenguaje. En aquella coyuntura, la configuración oficial de las tradiciones nacionales basada en el imaginario lingüísticocultural asociado a la pampa húmeda -que había sustentado el modelo agroexportador desde fines del siglo xix y la política de asimilación de los inmigrantes extranjeros (PRIETO, 2006; RUBIONE, 2006)- comenzaba paulatinamente a articularse con la inclusión de los llamados cancioneros populares y de la cultura considerada representativa de las provincias del Norte. Se podría plantear, pues, que se trató de un proceso de reformulación de las políticas estatales de construcción de la tradición, entendida no en términos esenciales sino -en palabras de Williams (2000)- como tradición selectiva.

Por otra parte, la emergencia y el posterior proceso de institucionalización de los estudios sobre el lenguaje folklórico 
norteño -que tendría como efecto la creación, en 1943, del Instituto Nacional de la Tradición, a cargo de Juan Alfonso Carrizoacompañaron en gran medida los discursos que tomaban como objeto de censura las nuevas formas de cultura popular urbana surgidas durante las primeras décadas del siglo xx. En particular, las prácticas culturales sobre las cuales recayeron mayormente las posiciones de censura fueron el teatro popular, en el que se incorporaban las variedades lingüísticas de los colectivos inmigrantes (PELLETIERI, 2008), y el tango, que mostraba la creciente incorporación del lunfardo -aquella variedad definida desde fines del siglo xix como "idioma del delito"- en la cultura popular de Buenos Aires (FRAGA, 2006).

Desde mediados de la década de 1930, el progresivo desarrollo de la radiodifusión profundizó las preocupaciones de los sectores dirigentes en torno de la cultura y del lenguaje populares (MATALLANA, 2006). Desde entonces, devino uno de los principales problemas glotopolíticos tanto para los sucesivos gobiernos nacionales (ARNOUX, VÁZQUEZ VILLANUEVA \& VITALE, 2003; VITALE, 2010) como para aquellos intelectuales del nacionalismo católico que - según explica Zanatta (2005) - veían en el nuevo medio de comunicación de masas una herramienta para el adoctrinamiento moral de la población, pero también un instrumento peligroso que debía ser controlado.

La AAL no fue ajena a tales procesos. Por el contrario, los $B A A L$ dieron lugar a numerosos artículos, discursos de recepción y notas que contribuían a configurar imaginarios en torno del lenguaje rural, del folklore, del lunfardo y de los géneros constituidos a través de aquellas variedades lingüísticas. En particular, los textos firmados por Ibarguren, por un lado, y los artículos que tomaban el folklore norteño, el lenguaje definido como rural y el lunfardo como objetos de saber mostraron el interés de la Corporación por institucionalizar la distinción entre aquello considerado parte de las tradiciones populares y las manifestaciones lingüístico-culturales asociadas a los sectores populares urbanos.

\section{Definiciones de país y formulaciones sobre el lenguaje: la palabra de Ibarguren}

Las diversas intervenciones textuales de Ibarguren en los $B A A L$ constituyen una zona del archivo privilegiada para analizar las posiciones que surgieron en el seno de la AAL durante sus primeras décadas de funcionamiento. Ibarguren fue, en efecto, una figura central en la Academia, por un lado por su papel institucional formal -además de haber sido uno de sus principales impulsores, representó oficialmente a la Corporación entre 1935 y 1955. Por el otro, las posiciones condensadas en sus textos expresan y a su vez configuran las problemáticas a las cuales buscaron dar respuesta los diversos análisis en torno del lenguaje popular enunciados en los BAAL durante el período 1933-1943. 
En los textos firmados por Ibarguren aparecen -a diferencia de la gran mayoría de los artículos de los Boletines- planteos políticos que incluyen definiciones de país y caracterizaciones acerca de la nación, que delimitan a su vez aquello que puede y debe ser dicho sobre la cultura y el lenguaje. De esta manera, la palabra de Ibarguren proporcionaba a la AAL y a sus actividades un sustento político general, que debía orientar las posiciones normativas de la Corporación.

La primera intervención pública de Ibarguren en el seno de la AAL fue en el marco del acto de recepción de Ángel Gallardo como miembro de la Corporación. En aquel contexto, Ibarguren destinó una parte de su discurso -publicado en el primer $B A A L-$ a caracterizar las tareas que debía asumir la Academia, vinculando los objetivos de la intervención político-lingüística de la AAL con la cuestión de la nación:

(1) La función primordial de una Academia de Letras es perfeccionar el lenguaje que mana del pueblo y es afinado por el ingenio de los escritores. En naciones de inmigración como la nuestra, tal tarea tiene una importancia mayor que en países tradicionales de población homogénea (IBARGUREN, 1933, p. 98).

La formulación transcripta en (1) contiene trazos de aquella representación de la nación que había operado como mecanismo legitimador de las políticas de castellanización de los inmigrantes extranjeros a principios del siglo xx (DI TULLIO, 2003; ENNIS, 2008). Ahora bien, en el fragmento citado la idea de que la Argentina constituía una nación de inmigración aparece mediante un efecto de evidencia que la naturaliza. La formulación actualiza, de esta manera, aquellas dicotomías entre inmigración y tradiciones, heterogeneidad y homogeneidad que constituyeron los sentidos dominantes de la discursividad estatal del período 1880-1910.

Este modo de definir la nación argentina y de delimitar, en relación con ello, las orientaciones de la AAL se mantuvo constante en los diversos discursos de recepción y textos de Ibarguren, en los cuales reaparecía con fuerza aquella imagen de la Argentina agroexportadora de la década de 1910. Una de las formulaciones que condensa con mayor precisión este imaginario de país formó parte de un texto, publicado en los $B A A L$ en 1939, en el cual se transcribía un discurso oral de Ibarguren:

(2) La Argentina más genuina y característica está en las campañas, en las provincias. Las urbes populosas no tienen por lo general acentuado tipo nacional, excepto aquellas que representan y conservan una tradición histórica peculiar. La fisonomía propia y la vida esencial de un país, sobre todo cuando es agrícola y pastoril, está en los campos (IBARGUREN, 1939, p. 563). 
El vocabulario que el texto despliega configura un entramado de sentidos en el cual "campañas", "provincias" y "campos" aparecen en términos generales como elementos discursivamente equivalentes. Esta equivalencia produce un efecto de homogeneidad que borra las distinciones entre provincias y zonas del país, construyendo una imagen idealizada de aquello que denomina "campos" o "campañas". El funcionamiento de tal vocabulario muestra la productividad que este imaginario seguía teniendo como mecanismo de contraste frente a las grandes ciudades, aquellos espacios percibidos como zonas donde se producían las mayores transformaciones sociales, culturales y económicas.

Esta fue la representación dominante, y constante, en las formulaciones mediante las cuales Ibarguren definía la Argentina y proyectaba la concepción de nación que debía orientar las actividades académicas. En efecto, en otro discurso de recepción, pronunciado ya en 1943, el entonces presidente de la Corporación reiteraba los mismos tópicos que habían sustentado aquella primera intervención de 1933:

(4) Nuestro país mantiene aun su fisonomía propia en las provincias del interior, a diferencia de las ciudades mercantiles del litoral y de sus puertos que recibieron una fluencia foránea que amenaza alterar nuestros rasgos originales. (...) Este fenómeno conspira contra nuestra integridad espiritual y puede modificar paulatinamente los caracteres de nuestra alma genuina (...). Es menester velar, en primer término, para que se conserven puras nuestras tradiciones (IBARGUREN, 1943, p. 54).

La última parte de la formulación citada en (3) permite observar el papel central que tenían a comienzos de la década de 1940 la persistencia del imaginario de amenaza asociado a la inmigración y la construcción de una determinada concepción de las tradiciones que operara como mecanismo de inclusiónexclusión de lo popular.

Este proceso discursivo de idealización de los espacios definidos como "el campo" y "la ciudad" tuvo efectos de sentido en las formulaciones sobre el lenguaje. En los primeros textos publicados en los $B A A L$, Ibarguren proyectaba aquella oposición a los elementos lingüísticos asociados típicamente, por un lado, a las expresiones del "gaucho" de la pampa húmeda y, por el otro, a determinadas prácticas lingüísticas propias de Buenos Aires:

(5) En la pampa, para no citar sino un ejemplo, el gaucho, como expresión la más ponderativa, dice delicadamente de mi flor, y - como observa Tiscornia - llama a una mujer hermosa "la flor del pago". Comparemos esas poéticas canciones y ese léxico con la jerga de suburbio de los tangos y la de algunos diarios porteños, que manchan con su grosera vulgaridad el habla y envenenan el alma de Buenos Aires (IBARGUREN, 1933, p. 99). 
En (4), la dinámica contrastiva se traslada a los modos de denominación metalingüística. Así, se configura la oposición entre "léxico" y "jerga", distinción que opera también en las concepciones en torno de los géneros discursivos: los tangos, asociados al lunfardo porteño, aparecen excluidos del sentido de "poéticas canciones". Asimismo, la exaltación de la naturaleza rural como elemento representativo de las tradiciones argentinas se proyecta a las formulaciones que predican acerca del lenguaje y de las palabras:

(6) En los campos los vocablos brotan lozanos, asoleados y jugosos cual frutas bien sazonadas; parece que el terruño les comunicara esa emanación misteriosa que da patria a las cosas y a los hombres; en la salubre atmósfera de las campañas, aquellos se modulan con tonos peculiares, vibran expresivos como el canto de las aves bajo los árboles o entre las mieses; allí se conservan puros a través de las generaciones (IBARGUREN, 1933, p. 98-99).

La cita transcripta en (5) pone de manifiesto que no solo el espacio de "el campo" era construido mediante un proceso de idealización; también las palabras eran concebidas como "frutos espontáneos" de la naturaleza, de manera tal que aparecían silenciados los sujetos y las relaciones sociales constitutivas de los procesos lingüísticos. Esta concepción ancla en gran medida en un imaginario que -siguiendo el análisis de Williams (2001)- podría asociarse con aquella caracterización de las églogas virgilianas de una edad de oro, en la cual la tierra producía sus frutos sin necesidad del trabajo humano y el tiempo se desarrollaba en una permanente continuidad. Este modo de representar los elementos lingüísticos asociados con "el campo" construía, por consiguiente, la idea de que aquellas palabras permanecían inmutables a lo largo del tiempo. Tal construcción de la temporalidad ahistórica y de la idea de pureza asociada al imaginario rural presentaba una brecha significativa respecto de los modos de representación del lenguaje urbano:

(7) El aluvión cosmopolita salpica la lengua de voces extrañas que ensucian y afean el habla, lo que es menester combatir con ahínco para conservar acendrado el riquísimo patrimonio idiomático que nos dio España. En las ciudades es donde pululan y se propagan con más intensidad los barbarismos (IBARGUREN, 1933, p. 98).

La ciudad era percibida, entonces, como el espacio en el cual se producían y se ponían en circulación los neologismos y los llamados barbarismos. Buenos Aires constituía, por este motivo, la zona lingüística sobre la cual debía recaer el mayor control y la más constante vigilancia, puesto que la misma dinámica de la ciudad hacía del lenguaje una instancia en permanente transformación. Se entramaban, así pues, en el texto de 1933, la exaltación de las expresiones asociadas típicamente al imaginario rural 
pampeano y la persistencia de aquellas posiciones de rechazo a las lenguas de inmigración que habían circulado desde fines del siglo xix.

Al igual que en las definiciones generales en torno de la Argentina, en las formulaciones acerca del lenguaje que se inscriben en los textos de Ibarguren publicados luego de 1933 se puede identificar un grado importante de estabilidad. Hay, no obstante, una diferencia: en lo que atañe a las formulaciones sobre la tradición en el lenguaje aparecen determinadas transformaciones discursivas, que dan cuenta del proceso de institucionalización del folklore y de construcción de los cancioneros considerados populares como objeto de valoración. Se trata, específicamente, no de sustituciones sino de agregados, que se incorporan a las formulaciones que retoman -incluso literalmente- los textos precedentes:

(8) En la pampa y en las montañas, entre los gauchos, los arrieros y los campesinos criollos es donde se halla con más fuerza el alma de España. Esa alma late no sólo en viejos vocablos y rancios modismos sino también en las formas expresivas de la sensibilidad y de la psicología popular. El folk-lore argentino, en una considerable porción de sus manifestaciones, es fruto y flor de semilla genuinamente española. Basta para probarlo echar una rápida ojeada a nuestros cancioneros y refraneros publicados por estudios enjundiosos como la notable obra de Juan Alfonso Carrizo (IBARGUREN, 1939, p. 564-565).

El fragmento citado da cuenta, en efecto, de la incorporación, en el seno de la AAL, de la cuestión del folklore norteño en los planteos acerca de la tradición, incorporación que se expresa textualmente mediante la yuxtaposición de nuevos elementos asociados con el paisaje del Norte de la Argentina- agregados a aquellos que ya aparecían en 1933.

Por otra parte, la concepción de la tradición en términos de cultura folklórica del Norte resultaba más confluyente con el modo en que el nacionalismo católico definía las tradiciones nacionales, esto es, como herencia de la España católica (ZANATTA, 2005). Las manifestaciones calificadas como "expresiones folklóricas", por consiguiente, eran concebidas -tal como se verá con mayor precisión en el apartado siguiente- como una continuidad de la tradición hispánica en la Argentina y también por ello eran caracterizadas discursivamente como un reservorio de la espiritualidad católica que particularmente las provincias del Norte del país habrían preservado.

No obstante, los textos de Ibarguren no realizaban distinción alguna entre las coplas recopiladas en los cancioneros de Carrizo y la poesía rural asociada a la pampa. Por el contrario, en sus formulaciones acerca del lenguaje popular y de las tradiciones consideradas "genuinas", Ibarguren construía un conjunto homogéneo con todos aquellos elementos lingüísticos que adquirieran el valor 
de lo tradicional. La inclusión de alusiones al folklore norteño no conllevaba, pues, desplazamientos de sentido significativos; es por ello que los últimos textos de Ibarguren publicados en los $B A A L$ durante el período 1933-1943 retomaban, aunque con una mayor generalidad, los mismos lineamientos político-lingüísticos que había enunciado en 1933 y en 1939:

(9) En naciones de inmigración como la nuestra la tarea de velar por la pureza del lenguaje tiene una importancia mayor que en países de población homogénea y de larga historia. La corriente cosmopolita altera la lengua con voces extrañas que ensucian y afean el habla, lo que es necesario combatir con ahínco para conservar acendrado el riquísimo patrimonio idiomático que nos legó España. La gran labor de cultura literaria nacionalista de recoger del manantial popular la voz adecuada y bella y depurar el lenguaje en procura del giro preciso es la que primordialmente deben realizar nuestros escritores para hacer una literatura de carácter argentino y contener la ola exótica y arrabalera que en la metrópoli y en nuestras populosas ciudades, repletas de forasteros, pugna por volcar su fango verbal (IBARGUREN, 1943, p. 56).

Los textos de Ibarguren señalaron, así, dos de los principales objetivos que orientaron diversos aspectos de la labor de la AAL durante sus primeras décadas de funcionamiento: la preservación del lenguaje considerado "genuinamente popular" y el control sobre "el lenguaje porteño", asociado -a través del funcionamiento de la expresión "arrabalera"- al lunfardo y al tango. De esta manera, Ibarguren no sólo enunciaba el proyecto político-cultural al que debían responder los lineamientos académicos; también delimitaba cuáles eran los objetos sobre los cuales debían recaer los análisis descriptivo-prescriptivos de quienes representaban, en el seno de la AAL, los saberes especializados en torno de la poesía considerada popular, del folklore y del lunfardo.

\section{Tradición y peligrosidad: lo popular como objeto de saber}

Las dos figuras con cuya mención Ibarguren daba sustento a sus posiciones, Juan Alfonso Carrizo y Eleuterio Tiscornia, eran referentes del desarrollo de dos campos del saber: el de los estudios sobre el folklore norteño y el de los estudios sobre poesía gauchesca. Estos enfoques tenían una importancia considerable en los $B A A L$, especialmente los estudios vinculados al folklore del Norte, por su funcionamiento en tanto modo de configuración de la tradición popular como objeto de valoración.

Ahora bien, Carrizo no solo representaba el saber especializado en torno de las tradiciones norteñas consideradas "genuinas" sino también la voz de aquel que había efectivamente observado los elementos lingüístico-culturales asociados a tales tradiciones. Su mención generaba, así, un doble efecto de sustentación: en el saber del folklorista y en el saber experimental del viajero-observador. El propio Carrizo, en sus relatos y descripciones, asimilaba su 
punto de vista y su experiencia como investigador y recopilador de cantares con aquella mirada del viajero, esto es, de quien observa prácticas discursivas y culturales ajenas a su propia cosmovisión.

Era esta construcción la que se ponía de manifiesto en uno de los principales artículos de los BAAL en los cuales Carrizo condensó su caracterización de la cultural lingüística popular del Norte argentino, texto publicado en 1936 bajo el título"La blasfemia y los cantares populares. Por qué no existe la blasfemia en nuestros criollos y por qué no hay procacidad en los cantares":

(10) El viajero que haya tenido la oportunidad de visitar el norte del país, y haya podido tratar con los paisanos nativos de las provincias que constituían el Tucumán colonial, habrá podido observar que de los labios de esa gente no sale nunca una blasfemia (...). Yo que he tenido la suerte de vivir con ellos mucho tiempo, buscando los cantares populares, he constatado que el criollo norteño y seguramente también el de las otras regiones del país no es maldiciente, no abre su boca para profanar el santo nombre de Dios (CARRIZO, 1936, p. 56).

$\mathrm{Al}$ igual que Ibarguren, Carrizo partía del supuesto de que había una continuidad entre las prácticas y tradiciones españolas, y aquellas de los "paisanos argentinos". La tesis de Carrizo consistía en afirmar que habían sido los mecanismos e instrumentos concretos de disciplinamiento de las instituciones eclesiásticas coloniales los que habían modificado las prácticas impías que traían los habitantes del norte de la Argentina:

(11) Frente al hecho, en cierto modo desconcertante, de nuestro paisano que habiendo heredado todo al español, no le haya aprendido también a blasfemar, he tratado de buscar la causa y creo haberla encontrado en la actitud decidida de los obispos y sacerdotes de los siglos de la conquista y colonización (CARRIZO, 1936, p. 56-57).

Siguiendo lo enunciado en el texto de Carrizo, la tradición más "pura" de la cultura popular nacional se encontraba, por consiguiente, en aquellas zonas donde había habido una mayor intervención disciplinante de las instituciones coloniales. Esta interpretación explicaba en gran medida los criterios de selección que habían conducido a Carrizo a privilegiar las provincias norteñas para la recopilación de las "coplas populares". Así pues, el texto de Carrizo configuraba una imagen piadosa de las prácticas discursivas de los "paisanos argentinos", asociada a la moral católica:

(12) En cuanto a los cantares (...) en las 14.000 piezas recogidas por mí, de boca del pueblo, no hay una blasfemia y no hay tampoco la procacidad de la copla española; hay sí, picardía, doble sentido, que puede hacer sonrojar a una niña pero no la copla grosera e impúdica (CARRIZO, 1936, p. 57).

Era, por consiguiente, aquella inocencia -manifestada en el lenguaje- la que se expresaba en las coplas y cantares populares, y 
la que se debía preservar a través, principalmente, de las prácticas de intervención de la AAL.

El interés por delimitar lo popular también se expresaba en los estudios sobre la llamada "poesía nacional". En este sentido, las definiciones y caracterizaciones que exponía Tiscornia en torno de aquellos géneros poéticos asociados a lo popular y/o a lo tradicional resultaban marcadamente coincidentes con los lineamientos generales de los artículos que versaban sobre cuestiones de folklore. Si bien fueron varias las notas publicados por Tiscornia en los $B A A L$, el texto más completo sobre poesía considerada popular apareció en el tomo extraordinario de 1943, con el título "Orígenes de la poesía gauchesca”. El objeto principal de aquel texto era, pues, definir, demarcar y delimitar las diferencias entre dos formas de la poesía definida como popular:

(13) El estudio de nuestra poesía popular ofrece dos manifestaciones sustancialmente diferentes: la tradicional y la gauchesca. La tendencia vulgar tira a confundirlas en un solo cuerpo, pero la crítica debe evitar esa confusión. La edad, el caudal temático, la zona geográfica de dispersión, el carácter popular son distintos en las dos (TISCORNIA, 1943, p. 347).

No obstante la necesidad de distinguirlas, ambas formas eran concebidas y definidas por Tiscornia como expresiones de la literatura popular. La primera, la poesía tradicional, era compartida por todos los países hispanoamericanos; se trataba de aquella poesía que Carrizo recogía en sus cancioneros:

(14) La poesía tradicional, en nuestro país, en toda América, remonta a los días de la conquista y colonización; es lo español de los romances viejos y las antiguas canciones de los siglos xvi y xvii, con los arrastres del siglo xv; transmite la sustancia lírica de los villancicos y las coplas, y la épica de los cantares heroicos y caballerescos; se conserva en las provincias andinas y norteñas, derramada en sus valles y montañas (TISCORNIA, 1943, p. 347).

La definición de Tiscornia sobre la poesía caracterizada como tradicional no sólo explicaba aquellos supuestos que regían los estudios del folklore. También proporcionaba elementos para comprender los motivos que habían llevado a Carrizo a confeccionar cancioneros por provincia: en cada región, provincia o zona aquella poesía tradicional adquiría rasgos locales peculiares y propios.

La poesía gauchesca, por su parte, era el objeto primordial de estudio de Tiscornia. Tal como aparecía definida en el texto de este autor, la gauchesca tenía las condiciones para representar -más que la poesía tradicional- aquel imaginario de cultura ganadera $\mathrm{y}$, en gran medida, la pampa húmeda como zona de referencia y alma mater de la nacionalidad. En efecto, el texto de Tiscornia configuraba una estrecha relación entre esta forma de la poesía y la cultura propia del "campo abierto": 
(15) La poesía gauchesca es posterior en casi tres siglos; recibe de la tradicional, en la herencia de la lengua, una porción considerable de las ideas y los sentimientos, pero tiene originalidad propia, fuertemente acentuada; se apodera de un nuevo escenario, que es el campo abierto, y de un tipo nuevo, que es el gaucho, y funda en ambas fuentes la razón de su existencia; se desarrolla en la llanura inmensa, a uno y otro lado del Plata, y alcanza en la inspiración de poetas individuales una expresión popular que puja por extenderse a todas partes como expresión nacional (TISCORNIA, 1943, p. 347-348).

De esta manera, Tiscornia se ocupaba de aclarar y distinguir aquello que en los textos de Ibarguren aparecía yuxtapuesto y entrelazado. Aun así, las dos formas definidas por Tiscornia como de poesía popular compartían una serie de elementos comunes, principalmente el remitir a un ámbito caracterizado mayormente por su lejanía y distancia socio-cultural respecto de las grandes ciudades. En un caso, se trataba de los "paisanos del Norte"; en el otro, de los "gauchos de la pampa"; en ambos casos la relación con la naturaleza aparecía como elemento constitutivo de la creación popular, fuera esta considerada anónima y colectiva, o autorial e individual.

Las intervenciones de Carrizo y de Tiscornia en los BAAL proporcionaban en gran medida un sustento epistémico al imaginario que valoraba lo popular en tanto parte constitutiva de las tradiciones, esto es, como rémora de un pasado previo al proceso de inmigración, en primer término, y de desarrollo urbano, en segundo término. Mostraban, pues, aquello a preservar, contribuyendo a institucionalizar el contrapunto entre la valoración de lo tradicional y las expresiones populares urbanas, excluidas de las definiciones en torno de lo popular. No obstante, los saberes que Tiscornia y Carrizo representaban no permitían legitimar la construcción del lunfardo en términos de amenaza a la nacionalidad, a la moralidad y a la lengua. Es por ello que resulta comprensible la publicación en los $B A A L$ de varios artículos que abordaban específicamente el lunfardo como objeto de descripción y explicación.

Los principales textos acerca del lunfardo publicados en los $B A A L$ fueron firmados por Rodolfo Senet, una de las figuras de la Escuela Positivista que adquirió notoriedad durante los primeros años del siglo xx (TALAK ET AL., 2005). Los supuestos epistemológicos que enmarcaban las explicaciones de Senet en torno del lenguaje urbano se filiaban en los estudios criminológicos encarados por el positivismo desde fines del siglo xix (SALVATORE, 2004). Tal perspectiva centraba sus análisis y clasificaciones en el concepto de "peligrosidad", que era comprendida como "el estado potencial del impulso antisocial de cada individuo" (CAIMARI, 2004, p. 88) y que podría ser medida a través de un diagnóstico que atendía a un conjunto de variables. Según expone Caimari 
(2004), una de las variables que la Criminología positivista -en base a los trabajos del italiano Lombroso- consideró para la determinación de la "peligrosidad" de los individuos fue, justamente, el lenguaje. En particular, en la Argentina esta perspectiva de análisis del "lenguaje criminal" se volcó, ya desde fines del siglo xix, a la descripción y caracterización del lunfardo, variedad que los primeros especialistas definían como "lengua del delito" o "argot criminal" (CAIMARI, 2004; ENNIS, 2008).

Senet expuso en los BAAL su teoría acerca del lunfardo especialmente en un artículo publicado bajo el título de "El falseamiento del castellano en la Argentina y lo que significan en realidad las palabras del lunfardo" (1938). En aquel texto, Senet -actualizando los lineamientos conceptuales y metodológicos de la Criminología- buscaba demostrar que la creación de palabras "lunfardas" constituía la manifestación de una desviación respecto de la norma social.

Los planteos de Senet acerca del lunfardo mostraban el grado de confluencia que el positivismo y el nacionalismo tradicionalista -perspectivas confrontadas en los inicios del siglo xx (TERÁN, 2004)- presentaban para la década de 1930, especialmente en torno de la regulación normativa de las prácticas lingüísticas populares. En efecto, el artículo "El falseamiento del castellano en la Argentina y lo que significan en realidad las palabras del lunfardo", además de filiarse en la perspectiva criminológica positivista, actualizaba aquellos tópicos y lugares comunes acerca del lenguaje urbano que aparecían en los textos de Ibarguren:

(16) En todo el territorio del país, nuestro castellano deja mucho que desear; pero donde se le habla peor es, sin duda, en la ciudad de Buenos Aires. (...) Desde allí se infiltra, en el país, no poco a poco, sino en forma harto veloz, la corrupción del idioma que trajeran de la madre patria los conquistadores y colonizadores de otros tiempos (SENET, 1938, p. 121-122).

Por otro lado, los análisis de Senet también confluían con otras caracterizaciones en torno del lunfardo formuladas en los $B A A L$ y que ponían de manifiesto una de las preocupaciones centrales de la Academia: el problema de la creación léxica popular y de la circulación de neologismos que tenían origen en los sectores populares urbanos.

Las definiciones sobre esta variedad lingüística que aparecían en artículos previamente publicados en los $B A A L$ retomaban, pues, las caracterizaciones del lunfardo como "lengua del delito", tal como aparecía en el artículo de Portnoy "Notas sobre la evolución del castellano en la Argentina" (1937). Este artículo se proponía mostrar que el lunfardo tenía una "gran capacidad migratoria", lo que motivaba en gran medida que constituyera el objeto al que se debía volcar especialmente el control y la vigilancia 
académica. Esta era, principalmente, la tesis de Portnoy en torno de la expansión del lunfardo fuera de los límites "del delito":

(17) Lo que importa señalar en lo referente al lunfardo es, por decirlo así, su extraordinario poder migratorio. Apenas existe voz de esa jerga que no haya cruzado el Plata para difundirse en el Uruguay y en el Brasil (especialmente en la provincia de Río Grande). Jacques Raimundo, profesor brasileño, ha observado que el argot del delincuente porteño, la jerigonza del turf y el vesre arrabalero están ampliamente representados en el vocabulario del vulgo de su patria. Y cita cientos de vocablos de origen bonaerense, todos muy expresivos (PORTNOY, 1937, p. 262).

La expresividad que se le asignaba al lunfardo constituía, justamente, el motivo por el cual esta variedad lingüística tenía alcance en diferentes clases, sectores sociales y zonas geográficas. El problema en torno del lunfardo ya no era, entonces, aquel de fines de siglo xix, cuando el conocimiento de esta variedad estaba asociado directamente al estudio del comportamiento y de las patologías de los "delincuentes". La principal preocupación de la Academia, condensada en el artículo citado de Portnoy y en los análisis de Senet, era la circulación de las voces identificadas como "lunfardas" fuera de su ámbito primigenio. A ello apuntaba el artículo de Senet, que establecía una distinción moral entre quienes utilizaban estas palabras y quienes las rechazaban. Así, Senet buscaba dar fundamento epistémico a un objetivo eminentemente normativo: evitar que los sectores medios y sobre todo los trabajadores incorporaran palabras caracterizadas como "lunfardas".

Con tal fin, Senet -a diferencia de Ibarguren- no apelaba a la pureza que presentaría ni el "lenguaje rural” ni el "lenguaje norteño". En cambio, proponía como eje de diferenciación la relación de los sujetos urbanos con el trabajo y el comportamiento social, retomando clasificaciones propias del discurso criminológico positivista:

(18) Aparte de la necesidad de la gente de bajo fondo y de mal vivir de disponer de un idioma incomprensible para la gente honrada, su mismo género de vida, anormal con respecto al de la generalidad, les obliga a neologizar (SENET, 1938, p. 128).

De esta manera, los estudios de Senet otorgaban un sustento legitimado en el saber científico a aquella idea de que el lunfardo constituía una "fuente de corrupción", estableciendo una línea de continuidad -y de causalidad- entre la "corrupción moral" de los hablantes y la producción de neologismos populares, que eran vistos, justamente, como mecanismos desviantes de la lengua. Así pues, la perspectiva positivista permitía instituir un criterio -con valor de cientificidad- para fundamentar intervenciones normativas en torno del lunfardo y de los géneros asociados a este. 


\section{Conclusiones}

El desarrollo del análisis presentado muestra la relevancia que adquirió en los BAAL publicados durante el período 1933-1943 la cuestión del lenguaje popular, problemática que apareció como inquietud tanto en aquellos textos que presentaban definiciones de carácter político-cultural general como en aquellos otros que se proponían abordarla desde los saberes legitimados en el seno de la Corporación.

Conjuntamente, y puestos en serie, los textos analizados participaron de la configuración de una discursividad que generaba un "efecto de bucolización", que conllevaba un doble movimiento: la delimitación de lo popular como un elemento "natural" de aquellas zonas distantes de los grandes centros urbanos que se habían constituido o se estaban constituyendo como espacio de referencia para la definición estatal de la tradición nacional, y la construcción de lo popular urbano como una amenaza social, lingüística y moral.

Ahora bien, dentro de esta discursividad común, se podría plantear que entre unos y otros hubo un funcionamiento complementario, articulado. Por un lado, los textos de mayor alcance político señalaron en gran medida los objetivos de la Corporación: "combatir" y "conservar" fueron las expresiones con las cuales Ibarguren condensó los lineamientos político-lingüísticos que debían guiar, en este aspecto, el trabajo de la AAL. Por el otro, las descripciones y explicaciones desplegadas en los artículos que apelaban a la legitimidad de un saber especializado daban sustento a los posicionamientos normativos y a los objetivos que la Corporación se planteaba en materia de regulación políticalingüística: los estudios sobre las coplas norteñas y sobre poesía gauchesca señalaban los elementos a "conservar"; la explicación criminológica proporcionaba una batería de argumentos para "combatir" el uso de neologismos populares asociados al lunfardo. En este sentido, el análisis da cuenta de la productividad política y disciplinaria de la serie de artículos analizados, que contribuyeron a institucionalizar una visión tradicionalista sobre la cultura y sobre lo popular en el lenguaje.

\section{Resumo}

O artigo propõe-se analisar as posições e os saberes sobre a linguagem popular formulados nos Boletins da Academia Argentina de Letras (BAAL) durante os primeiros dez anos da publicação (1933-1943). Trata-se de uma problemática recorrente nos $B A A L$, e de forte relevância histórica a partir das transformações socioeconômicas, politicas e culturais que tiveram lugar desde os 
inícios da década de 1930. Em termos teóricos, o trabalho filia-se nos estudos de Glotopolítica tal como se desenvolvem atualmente na Argentina, considerando na sua vez aportes de diferentes perspectivas disciplinares. Metodologicamente, $o$ trabalho coloca em serie formulações sobre a Argentina, sobre a linguagem e os gêneros associados ao popular que -na sua dispersão-respondem ao mesmo posicionamento político-institucional. Por sua importância discursiva, a análise se detém especialmente sobre o funcionamento da dicotomia campo-cidade, privilegiando dois eixos: a) a relação entre as definições políticas gerais que se formulam nos BAAL e os posicionamentos sobre a cultura e a linguagem popular e b) os saberes especializados que constroem o lunfardo, o folclore e a poesia considerada popular como objetos de descrição e prescrição. O trabalho propõe-se, assim, dar conta dos modos nos quais a Academia contribuiu a institucionalizar um imaginário de linguagem popular vinculado, de um lado, a uma determinada definição da tradição e, de outro, às políticas de exclusão das práticas associadas ao espaço popular urbano.

Palavras-chave:Glotopolitica, Academia Argentina de Letras, linguagem popular, lunfardo, folclore, tradição.

\section{REFERÊNCIAS:}

ARNOUX, Elvira Narvaja de. Los discursos sobre la nación y el lenguaje en la formación del Estado (Chile, 1842-1862). Estudio glotopolítico. Buenos Aires: Santiago Arcos, 2008.

ARNOUX, Elvira Narvaja de \& DEL VALLE, José. Las representaciones ideológicas del lenguaje: Discurso glotopolítico y panhispanismo. Spanish in Context, v. 7, n. 1, p. 1-24, 2010.

ARNOUX, Elvira Narvaja de \& BEIN, Roberto (comps.). La regulación política de las prácticas lingüísticas. Buenos Aires: EUDEBA, 2010.

ARNOUX, Elvira Narvaja de \& LUIS, Carlos (comps.). El pensamiento ilustrado y el lenguaje. Buenos Aires: EUDEBA, 2003.

ARNOUX, Elvira Narvaja de, VÁZQUEZ VILLANUEVA, Graciana \& VITALE, Alejandra. Regulación del lenguaje y control de la moral y el civismo en la normativa estatal sobre la radiodifusión. In: ARNOUX, Elvira Narvaja de \& LUIS, Carlos (comps.). El pensamiento ilustrado y el lenguaje. Buenos Aires: EUDEBA, p. 233-268, 2003. 
AUROUX, Sylvain (dir.). Histoire des idées linguistiques. Bruxelles: Mardaga, 1989.

- - - A revolução tecnológica da gramatização. Campinas, SP: Ed. da UNICAMP, 1992.

BARRIOS, Graciela. La función política de las academias de la lengua. In: BEHARES, Luis E. (comp.). V Encuentro internacional de investigadores de políticas lingüísticas. Montevideo: Universidad de la República y Asociación de Universidades Grupo Montevideo, p. 31-36, 2010.

BLANCO, Mercedes Isabel. Ejemplaridad y autoridad idiomáticas: La Academia Argentina de Letras. In: Estudios sobre el español de la Argentina,v. III. Bahía Blanca: Departamento de Humanidades - Universidad Nacional del Sur, p. 79-124, 1994.

- - - "La Academia Argentina de Letras y el español de la Argentina". Cuadernos Americanos nueva época, v. 52, p. 254-269, 1995. BUCHRUCKER, Christian. Nacionalismo y peronismo: la Argentina en la crisis ideológica mundial [1927-1955].Buenos Aires: Sudamericana, 1999 [1987].

CAIMARI, Lila. Apenas un delincuente. Crimen, castigo y cultura en la Argentina, 1880-1955. Buenos Aires: Siglo Veintiuno, 2004.

DEL CAMPO, Hugo. Sindicalismo y peronismo. Los comienzos de un vínculo perdurable. Buenos Aires: Siglo XXI, 2005.

DI TULLIO, Ángela. Políticaslingüísticas e inmigración. El caso argentino. Buenos Aires: EUDEBA, 2003.

ENNIS, Juan Antonio. Decir la lengua. Debates ideológico-lingüísticos en la Argentinadesde 1837.Frankfurt am Main, Berlin, Bern, Bruxelles, New York, Oxford, Wien: Peter Lang, 2008.

FRAGA, Enrique. Laprohibición del lunfardo en la radiodifusión argentina 1933-1953. Buenos Aires: Lajouane, 2006.

GLOZMAN, Mara R. La Academia Argentina de Letras y el peronismo (1946-1956). Anclajes, v. XIII, n. 13, p. 129-144, 2009.

MATALLANA, Andrea. "Locos por la radio". Una historia social de la radiofonía en la Argentina, 1923-1947. Buenos Aires: Prometeolibros, 2006.

ORLANDI, Eni P. Lingua e conhecimento lingüístico. Para uma História das Idéias no Brasil. São Paulo: Cortez Editora, 2002.

PELLETIERI, Osvaldo. El sainete y el grotesco criollo: del autor al actor. Buenos Aires: Galerna, 2008.

PRIETO, Adolfo. Eldiscurso criollista en la formación de la Argentina moderna. Buenos Aires: Siglo Veintiuno, 2006 [1988].

SALVATORE, Ricardo. Criminología positivista, reforma de prisiones y la cuestión social/obrera en Argentina. In: SURIANO, Juan (comp.). La cuestión social en Argentina 1870-1943. Buenos Aires: Editorial La Colmena, p. 127-158, 2004. 
TABOADA, María Stella. Exclusión y dependencia lingüística. La política de la Academia Argentina de Letras. In: Centro Interdisciplinario de Política y Planificación Lingüísticas (ed.). Lenguaje, educación e ideología. Tucumán: Facultad de Filosofía y Letras Universidad Nacional de Tucumán, p. 65-108, 1999.

TALAK, Ana María et al. Novedad y relevancia en la historia del conocimiento psicológico. Anuario de investigaciones de la Facultad de Psicología - Universidad de Buenos Aires, v. XII, p. 305-313, 2005.

TERÁN, Oscar 2004. Ideas e intelectuales en la Argentina (18801980). In: TERÁN, Oscar (coord.). Ideas en el siglo. Intelectuales y cultura en el siglo $x x$ latinoamericano. Buenos Aires: Siglo XXI, p. 13-95, 2004.

VITALE, Alejandra. En torno de la lengua en la radio argentina. La encuesta de la Comisión Parlamentaria de 1938. In: ARNOUX, Elvira Narvaja de \& BEIN, Roberto (comps.). La regulación política de las prácticas lingüísticas. Buenos Aires: EUDEBA, p. 73-99, 2010. WILLIAMS, Raymond. Marxismo y literatura. Barcelona: Península, 2000 [1977].

- - - El campo y la ciudad. Buenos Aires: Paidós, 2001 [1973].

ZANATTA, Loris. Del Estado liberal a la Nación católica. Iglesia y Ejército en los orígenes del peronismo. 1930-1943. Bernal: Universidad Nacional de Quilmes, 2005 [1996].

\section{MATERIALES DE ARCHIVO}

“Decreto de creación”. In: Academia Argentina de Letras 1931-2001. Buenos Aires: Academia Argentina, p. 8-9, 2001.

CARRIZO, Juan Alfonso. La blasfemia y los cantares populares. Por qué no existe la blasfemia en nuestros criollos y por qué no hay procacidad en los cantares. BAAL, t. IV, p. 56-57, 1936.

IBARGUREN, Carlos. Discurso de don Carlos Ibarguren. BAAL, t. I, p. 97-110, 1933.

IBARGUREN, Carlos. El espíritu y la cultura hispánica en la expresión popular argentina. BAAL, t. VII, p. 97-110, 1939.

BARGUREN, Carlos. El sentido nacional en nuestra literatura. $B A A L$, t. XII, p. 5-9, 1943.PORTNOY, Antonio. Notas sobre la evolución del castellano en la Argentina. BAAL, t. V, p. 249-265, 1937. SENET, Rodolfo. El falseamiento del castellano en la Argentina y lo que significan en realidad las palabras del lunfardo. BAAL, t. VI, p. 121-144, 1938.

TISCORNIA, Eleuterio. Orígenes de la poesía gauchesca. BAAL, t.XII, p. 347-371, 1943 